bioRxiv preprint doi: https://doi.org/10.1101/2020 10.06.327288; this version posted November 27, 2020. The copyright holder for this preprint (which was not certified by peer review) is the author/funder, who has granted bioRxiv a license to display the preprint in perpetuity. It is made available under aCC-BY-NC-ND 4.0 International license.

\title{
Ablation of Proliferating Osteoblast Lineage Cells After Fracture Leads to Atrophic Nonunion in a Mouse Model
}

Katherine R. Hixon ${ }^{1}$ PhD, David A.W. Sykes ${ }^{2}$ BS, Susumu Yoneda ${ }^{1}$ MD, Jennifer A. McKenzie ${ }^{1}$ PhD, Austin Hensley ${ }^{1,3}$ MEng, Evan G. Buettmann ${ }^{1,3} \mathrm{PhD}$, Dimitrios Skouteris ${ }^{1} \mathrm{MD}$, Anna N. Miller ${ }^{1}$ MD, and Matthew J. Silva ${ }^{1,3} \mathrm{PhD}$

${ }^{1}$ Department of Orthopaedic Surgery; ${ }^{2}$ Department of Biology; ${ }^{3}$ Department of Biomedical Engineering; Washington University in St. Louis

Running Title: 5 words max

Fracture Healing Requires Proliferating Osteoblasts

Corresponding Author:

Katherine Hixon

BJCIH 11th Floor, RM 11302

Campus Box 8233

Orthopaedic Surgery

(314) 747-6070

khixon@wustl.edu 


\section{ABSTRACT}

Nonunion is defined as the permanent failure of a fractured bone to heal, often necessitating surgical intervention. Atrophic nonunions are a subtype that are particularly difficult to treat. Animal models of atrophic nonunion are available; however, these require surgical or radiation-induced trauma to disrupt periosteal healing. These methods are highly invasive and not representative of many clinical nonunions where osseous regeneration has been arrested by a "failure of biology". We hypothesized that arresting osteoblast cell proliferation after fracture would lead to atrophic nonunion in mice. Using mice that express a thymidine kinase (tk) "suicide gene" driven by the 3.6Col1a1 promoter (Col1-tk), proliferating osteoblast lineage cells can be ablated upon exposure to the nucleoside analog ganciclovir (GCV). Wild-type (WT; control) and Col1-tk littermates were subjected to a full femur fracture and intramedullary fixation at 12 weeks age. We confirmed abundant tk+ cells in fracture callus of Col-tk mice dosed with PBS. The remainder of mice were dosed with GCV twice daily for 2 or 4 weeks. Histologically, we observed diminished periosteal cell proliferation in Col1-tk mice 3 weeks post fracture. Moreover, Col1-tk mice had less osteoclast activity, mineralized callus, and vasculature at the fracture site compared to WT mice. Additional mice were monitored for 12 weeks with in vivo radiographs and microCT scans, revealing delayed bone bridging and reduced callus size in Col1-tk mice.

Following sacrifice, ex vivo microCT and histology demonstrated failed union with residual bone fragments and fibrous tissue in Col1-tk mice. Biomechanical testing demonstrated a failure to recover torsional strength in Col1-tk mice, in contrast to WT. Our data indicates that suppression of proliferating osteoblast-lineage cells for at least 2 weeks after fracture blunts the formation and remodeling of a mineralized callus leading to a functional nonunion. We propose this as a new murine model of atrophic nonunion.

Five Key Words: Injury/Fracture Healing, Genetic Animal Models, Preclinical Studies, Biomechanics 


\section{Introduction}

Nonunion is defined as the permanent failure of a fractured bone to heal, where surgical intervention is often required to achieve healing. (1) The reported clinical rate of nonunion is $5 \%$, with an estimated 500,000 fractures resulting in nonunion in the United States each year. ${ }^{(2-4)}$ Due to the necessary advanced care, treatment can cost upwards of $\$ 90,000$ per individual. ${ }^{(5)}$ Nonunions are caused by a variety of factors such as infection, avascularity, or lack of stability, and are broadly categorized as hypertrophic or atrophic, each of which require different treatment options. ${ }^{(1,6)}$ Of these, atrophic nonunion (characterized by absent or minimal callus formation) is the least understood and the most difficult to treat. ${ }^{(6,7)}$ Available animal models for atrophic nonunion involve highly invasive methods such as local periosteal stripping, bone marrow removal, devascularization, or the creation of a critical-sized defect. ${ }^{(6,8)}$ Such invasive methods are not representative of many clinical nonunions which are due to the disturbance of biological pathways. ${ }^{(1,9,10)}$ Thus, there is an unmet need for a clinically relevant "failure of biology" atrophic nonunion animal model in which therapeutic interventions could be tested.

Proliferation of periosteal cells occurs during fracture healing, providing a source of callus osteoblasts and chondrocytes. ${ }^{(6,11-13)}$ Previous work in rodents has shown that cell proliferation in periosteal callus is elevated as early as 2 days and remains elevated through 14 days after fracture, as shown by expression of proliferating cell nuclear antigen (PCNA). ${ }^{(14-16)}$ These observations suggest that the first 2 weeks are a critical period for cell proliferation during rodent fracture healing. They further suggest that impaired cell proliferation during this period will lead to blunted callus formation, which may in turn result in atrophic nonunion. To our knowledge, it has not been shown that proliferation of periosteal progenitors in the early post-fracture period is required for successful healing.

While the progression of proliferation during fracture healing has been described, the molecular identity of these proliferating cells remains unclear. Recent reports of periosteal progenitors that contribute to fracture callus have used lineage tracing to identify a number of non-unique genes that mark this population. ${ }^{(17)}$ Earlier work demonstrated high GFP reporter expression in periosteal cells of 3.6Col1a1-GFP mice and showed that 3.6Col1a1 marks cells of the osteoblast lineage, from pre-osteoblasts to mature osteoblasts. ${ }^{(18)}$ We recently reported that proliferation of the 3.6Col1a1 cell population contributes to periosteal bone formation after noninjurious mechanical loading ${ }^{(19)}$, leading us to hypothesize that this population may also be critical to fracture healing, which is a largely periosteal-driven process. ${ }^{(20)}$ Jilka et al. ${ }^{(21)}$ developed 3.6Col1a1-tk (Col1-tk) mice in which proliferating osteoblast lineage cells can be ablated through exposure to the nucleoside analog ganciclovir (GCV). In the presence of GCV, replicating cells expressing a thymidine kinase (tk) "suicide gene" convert GCV to a toxic nucleotide which is incorporated into the DNA resulting in targeted cell death. ${ }^{(21)}$ This model provides a unique tool to test the requirement of proliferation of a defined population of periosteal cells to fracture healing.

The central hypothesis of this study is that proliferation of periosteal osteoblast-lineage cells is required for fracture healing. We created midshaft femur fractures in young-adult Col1-tk mice, and treated them with GCV for 2 or 4 weeks to ablate proliferating osteoblast-lineage cells, followed by withdrawal. Wildtype (WT) littermate control mice were treated identically. Healing was assessed by in vivo serial radiography and 
microCT, followed by terminal assessment at 3- and 12-weeks post fracture using histology, microCT and mechanical testing. Our findings show that suppression of proliferating osteoblast-lineage cells for either 2 or 4 weeks after fracture blunts the formation and remodeling of a mineralized callus and leads to a non-functional fibrous nonunion. We propose this as a novel "failure of biology" murine model of atrophic nonunion.

\section{Materials and Methods}

\section{Mouse Lines}

A total of 132 male and female mice at 12 weeks of age were used. All experimental procedures were approved by the Institutional Animal Care and Use Committee (IACUC) at Washington University in St. Louis in accordance with the Animal Welfare Act and PHS Policy on Humane Care and Use of Laboratory Animals. Transgenic 3.6Col1A1-tk (Col1-tk) mice (provided by Drs. Robert Jilka and Charles O'Brien) were used to target replicating osteoblast progenitors. ${ }^{(21)}$ Specifically, these mice were developed to express the herpes simplex virus thymidine kinase (HSV-tk, or 'tk' for short) gene, driven by the $3.6 \mathrm{~kb}$ rat Col1A1 promoter which is active in osteoblast lineage cells. In the presence of the nucleoside analog ganciclovir (GCV), replicating osteoblast progenitors expressing thymidine kinase (tk) convert GCV to a toxic version of the nucleotide which is then incorporated into the DNA. Following integration, the DNA strands break, resulting in cell apoptosis (Figure 1D). ${ }^{(21)}$ To generate Col1-tk mice, male C57BL6/J (The Jackson Laboratory, \#000664) mice were bred to female mice heterozygous for the tk transgene (tk-positive). This resulted in both heterozygous tk-positive (Col1-tk) and tk-negative (wildtype, WT) mice. Note that only one allelic copy of the tk transgene is necessary, and male Col1-tk mice are sterile. Genotyping was completed by Transnetyx using toe biopsies from the mice for real-time PCR (probe: puro). Subsequent breeding was completed using littermates (Col1-tk females and tk-negative males). All mice were group-housed up to five mice per cage under standard 12-hour light/dark cycle and given full access to food and water. Breeders were given high-fat chow and after weaning all mice were given normal chow. In a pilot study, two control groups were examined (WT dosed with GCV; and Col1-tk dosed with vehicle $\left(\mathrm{H}_{2} \mathrm{O}\right)$ ); histology and microCT demonstrated that both groups had normal appearing callus, with comparable bone volume and volumetric bone mineral density (data not shown). We chose WT dosed with GCV as the control group for all subsequent studies. All mice were dosed with ganciclovir (GCV, $8 \mathrm{mg} / \mathrm{kg}$ 
i.p., McKesson, San Francisco, CA) twice daily (Figure 1A) starting at the day of fracture (12 weeks of age). Mice were euthanized by $\mathrm{CO}_{2}$ asphyxiation at designated endpoints from 1 to 12 weeks after fracture.

Thymidine Kinase (tk) Expression in Fracture Callus

In a subset of mice $(n=15)$, WT mice were dosed with GCV and Col1-tk mice were dosed with either GCV or vehicle $\left(\mathrm{H}_{2} \mathrm{O}\right)$ for 2 weeks after fracture. Immunohistochemistry on decalcified, paraffin-embedded sections was used to visualize expression of tk in fracture callus as detailed below.

\section{Proliferation Assessment Study}

To assess proliferation following GCV drug withdrawal, 5-Ethynyl-2'-deoxyuridine (EdU, $0.2 \mathrm{mg} / \mathrm{mL}$ in 5\% sucrose) was added daily to the drinking water of two subsets of mice. First, for 2 weeks after fracture mice were treated with GCV but not EdU. During the next (third) week, mice received EdU but not GCV. After this third week, the mice were sacrificed to analyze the cumulative proliferative response (EdU staining), i.e., during the week after removal of the anti-proliferative conditions (Figure 1B). In a second subset, Col1-tk mice were fractured and immediately given EdU with or without the addition of GCV for 1 week to assess proliferation immediately following fracture and then sacrificed to visualize EdU histologically (Figure 1B).

\section{Fracture Healing Study}

In healthy mice, complete bridging of the fracture site with bony callus occurs 3-4 weeks after fracture. ${ }^{(22,23)}$ In humans, fractured long bones typically heal within 2-3 months and nonunions are clinically diagnosed after 6-9 months of nonhealing, i.e., 3-times the normal healing time. ${ }^{(22,24)}$ Thus, it has been proposed that a conservative assessment of nonunion in mice should be based on evaluation at 12 weeks post fracture. ${ }^{22,25)}$ For the main aim of the study, mice were dosed with GCV following fracture to target both the proliferative phase ( 2 week dosing) as well as the interval during which normal fracture healing occurs (4 week dosing). Following dosing for 2 or 4 weeks, GCV was then withdrawn and weekly monitoring of fracture healing continued through sacrifice (12 weeks) to evaluate healing (Figure 1C). Following euthanasia, animals were randomly assigned to either histological or biomechanical evaluation. 
A

\begin{tabular}{c|c|c}
\hline $\begin{array}{c}\text { Experimental } \\
\text { Group }\end{array}$ & $\begin{array}{c}\text { Abbreviation } \\
\text { (Genotype) }\end{array}$ & $\begin{array}{c}\text { Ganciclovir (GCV) } \\
\text { Dosing Scheme }\end{array}$ \\
\hline Wild-Type & WT (tk-) & Twice Daily \\
\hline 3.6Col1a1-tk & Col1-tk (tk+) & Twice Daily \\
\hline
\end{tabular}

GCV by i.p. injection $(8 \mathrm{mg} / \mathrm{kg}$ ) Twice daily

EdU in drinking water

$(0.2 \mathrm{mg} / \mathrm{mL}$ in $5 \%$ sucrose)

Changed daily

B
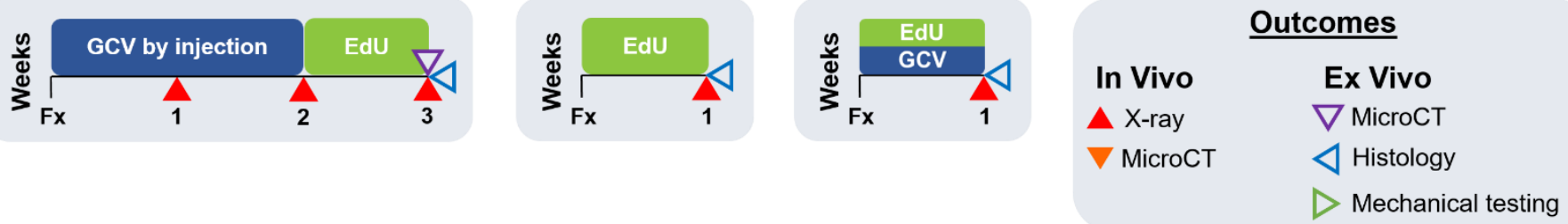

C
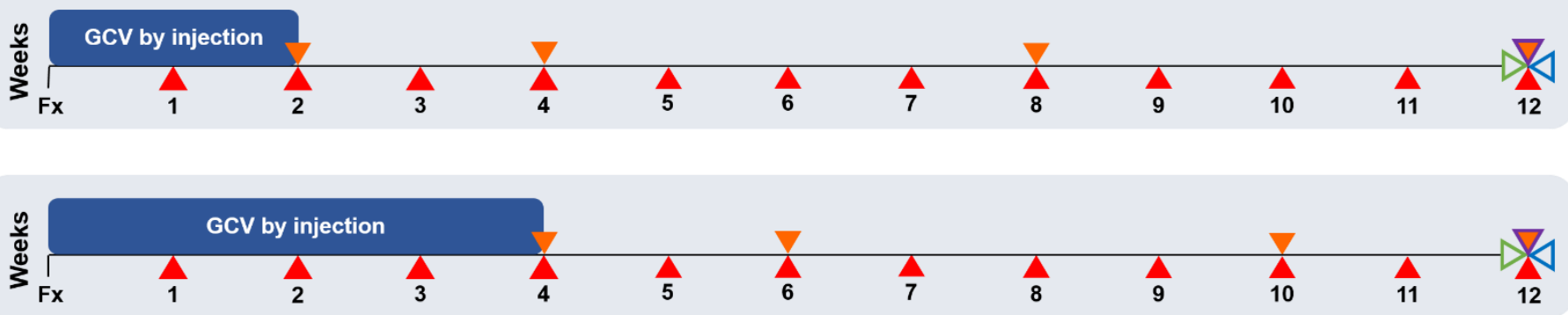

D

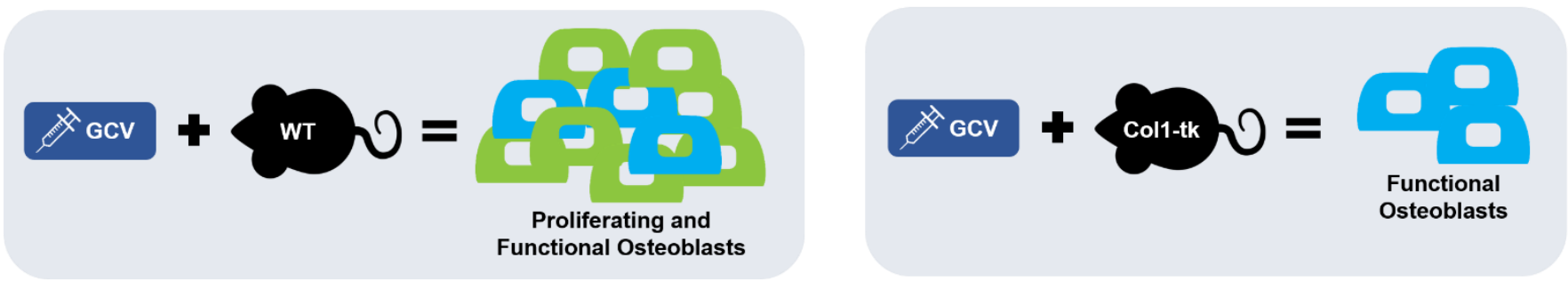

Figure 1. Experimental overview. Unilateral femur fractures were created in mice at 12 weeks age. (A) Both Col1-tk (tk-positive) and WT (tk-negative) mice were dosed with GCV, twice daily. (B) To assess proliferation, mice were dosed for 2 weeks and then given EdU in their drinking water for an additional week. Outcomes included weekly X-rays as well as microCT and histology post mortem. Another set of Co1-tk mice received 1 week of EdU, starting immediately after fracture, with or without GCV. (C) To assess the potential for recovery from suppressed osteoblast proliferation, mice were dosed with GCV for both 2 and 4 weeks before withdrawal, and then assessed by X-rays and in vivo microCT until sacrifice at 12 weeks. Ex vivo evaluation included microCT, histology, and mechanical testing. (D) In this experimental model, WT mice dosed with GCV have an increase in proliferating osteoblasts in addition to the resident functional osteoblasts. In contrast, Col1tk mice only have resident functional osteoblasts present due to the ablation of proliferating osteoblasts with GCV administration.

\section{Fracture Model}

A previously established protocol was used to create full fracture in the right femur of 12-week-old mice. ${ }^{(26)}$ Briefly, a transverse force was applied across the right femoral mid-diaphysis using a custom 3-pt bending setup (DynaMight 8841 ; Instron) creating a fracture. Following injury, the femur was stabilized using a 24- 
gauge metal pin (MicroGroup) and the wound closed using 3-0 nylon sutures (Ethicon). Fixation was confirmed by radiograph (Faxitron Ultrafocus 100; Faxitron Bioptics) immediately following surgery. This model mimics classical fracture injury and healing ${ }^{(27,28)}$, with both intramembranous bone formation and endochondral healing around the periphery and within the fracture gap, respectively. ${ }^{(23,29)}$ All mice were given buprenorphine SR (1 mg/kg, s.c.) for analgesia 1 hour before surgery.

\section{$\underline{\text { Radiographic Evaluation }}$}

Lateral radiographs were taken weekly following full fracture until euthanasia (3X magnification; Faxitron UltraFocus100; $n=12-18$ /group). All radiographs were blindly scored for the degree of healing using a modified Goldberg score (i.e. 0 = no bridging, 1 = one side bridged, 2 = complete bridging) ${ }^{(30)}$ Mice were excluded from the study if there was a loss of fixation during healing (total 18 mice).

\section{Micro-Computed Tomography}

In vivo scans were performed at 2, 4, 8, and 12 weeks, or 4, 6, 10, and 12 weeks for 2 and 4 weeks of GCV dosing, respectively ( $n=7-9 /$ group). For each scan, the animal was anesthetized (1-3\% isoflurane gas) and both femurs were scanned simultaneously using microCT (VivaCT 40, Scanco Medical AG, Switzerland; 15 $\mu \mathrm{m}$ voxel size, $70 \mathrm{kV}, 114 \mu \mathrm{A}$, and $300 \mathrm{~ms}$ integration time). This resulted in an estimated local radiation exposure of 42 cGy/scan; no impairments in callus healing in WT mice were noted. (31) Due to the artifact from the metal pin, threshold- or density-based measurements using Scanco software could not be performed. The proximal and distal ends of the callus were visualized, and a measurement of 3D distance between the center of the two sections was calculated $(\mathrm{mm})$. Contour lines were drawn around the outer edge of the callus and the callus volume was output as total tissue volume $\left(\mathrm{TV}, \mathrm{mm}^{3}\right)$. For ex vivo scans, femurs were dissected from the surrounding tissue and fracture fixation pins were removed ( $\mathrm{n}=15-18 / \mathrm{group})$. Femurs were scanned using microCT (VivaCT 40, Scanco Medical AG, Switzerland; $10.5 \mu \mathrm{m}$ voxel size, $55 \mathrm{kV}, 145 \mu \mathrm{A}, 300$ ms integration time). Analysis regions of interest (ROIs) differed for ex vivo 3 and 12 week femurs due to changes in callus length over time. For femurs dissected at 3 weeks ( $n=12 /$ group), a 600 slice (6.3 mm length) ROI was centered at the midpoint of the fracture line and a threshold of 160 per mille was used. The ROI length was selected to include the entire callus region of all samples. Each callus was contoured around its periphery, and the ROI included the original cortical bone plus the callus. Outcomes were total bone volume $\left(\mathrm{BV}, \mathrm{mm}^{3}\right)$, tissue volume $\left(T V, \mathrm{~mm}^{3}\right)$, volumetric bone mineral density (vBMD, $\left.\mathrm{mg} \mathrm{HA} / \mathrm{cm}^{3}\right)$, and tissue mineral density (TMD, mg $\mathrm{HA} / \mathrm{cm}^{3}$ ). At 12 weeks post fracture ( $\left.\mathrm{n}=14-17 / \mathrm{group}\right)$, a region of interest (ROI) of 200 total slices $(2.1 \mathrm{~mm})$ was identified, centered at the point of fracture, and the threshold was set to 350 per mille. This smaller ROI length reflected the shorter extent of mineralized callus at this timepoint. Due to remodeling of the callus, fracture lines were not visible at 12 weeks, thus the point of fracture was inferred from radiographic images at 2 weeks post fracture (femoral head to fracture midpoint distance). Contours around the periosteal bone surface were 
drawn and BV, TV, vBMD, and TMD were determined. Following ex vivo scanning, the femurs were either decalcified and processed for histology, or prepared for mechanical testing.

\section{$\underline{\text { Histological Analysis }}$}

To confirm the specific targeting of tk+ cells with GCV, immunohistochemistry (IHC) was used to detect the HSV tk protein at 2 weeks post fracture. ${ }^{(21)}$ Briefly, the paraffin slides were deparaffinized in xylene and rehydrated in graded ethanols. Incubation with $3 \% \mathrm{H}_{2} \mathrm{O}_{2}(5 \mathrm{~min})$ blocked endogenous peroxidases.

Endogenous epitopes were blocked with 10\% goat serum (abcam - ab7481) in PBS at room temp (1 hour). The sections were then incubated with rabbit polyclonal anti-HSV tk (1:100; gift from William Summers, Yale) at room temp (3 hours). The secondary antibody incubation and chromogenic HRP development were completed according to manufacturer's instructions (Dako Envision HRP System; K4010). Sections were counterstained with Modified Mayer's hematoxylin (Electron Microscopy Services 26041 - 05) and imaged at 20x on a Nanozoomer slide scanner (Hamamatsu Photonics).

Femurs from mice given EdU designated for frozen processing following fracture ( $\mathrm{n}=7 / \mathrm{group}$ ) were dissected and fixed immediately in paraformaldehyde for 48 hours, followed by decalcification in 14\% EDTA (pH 7.0) for 2 weeks. Samples were rinsed in PBS, infiltrated in 30\% sucrose, and embedded in optimal cutting temperature compound (OCT compound, Tissue-Tek; VWR). A Cryojane Tape Transfer System (Leica) was used to create frozen longitudinal sections of the decalcified bone (Leica CM 1950 Manual Cryostat) at $5 \mu \mathrm{m}$ thickness. Following sectioning, Click-iT EdU Alexa Fluor 647 Imaging Kit from ThermoFisher (C10340) was used to stain the sections for EdU and 4',6-diamidino-2-phenylindole (DAPI; \#D9542; 1:1000 dilution; SigmaAldrich, St. Louis, MO, USA). Briefly, frozen sections were thawed, washed with PBS, and permeabilized in $0.5 \%$ Triton X-100 (in PBS) for 20 min. The samples were then rinsed with PBS and incubated with $100 \mu \mathrm{L}$ of the reaction cocktail (1x Click-iT reaction buffer, $\mathrm{CuSO}_{4}, 1 \mathrm{x}$ buffer additive, and Alexa Flour azide) for $30 \mathrm{~min}$. Following additional rinsing in PBS, the slides were counterstained with DAPI. The whole femur was imaged using the Zeiss Axio Scan.Z1 slide scanner (20x objective) and images were assessed qualitatively for the presence of EdU-positive cells (pink).

Femurs designated for paraffin processing ( $n=4 /$ group for EdU 3 week timepoint and $n=7-8 /$ group for 12 week timepoint) were dissected and fixed immediately in 10\% neutral buffered formalin for 24 hours, followed by decalcification in 14\% EDTA ( $\mathrm{pH} 7.0$ ) for 2 weeks. Standard paraffin processing was used such that fractured femurs were cut as longitudinal sections at a $5 \mu \mathrm{m}$ thickness. Sections were stained with Picrosirius Red/Alcian Blue and the whole femur was imaged at 20x on a Nanozoomer slide scanner. Images were assessed qualitatively for callus composition and morphology.

The presence of osteoclasts was assessed using tartrate-resistant acid phosphatase (TRAP) staining on paraffin sections. Slides were manually evaluated to assess osteoclasts on the peripheral surface of the callus (osteoclast length/callus length (\%)) and the percent of the callus surface occupied by cartilage, fibrous tissue, and bone was quantified. Note that for the 3 week animals, the periphery of the entire callus (top and bottom) 
was analyzed for both WT and Col1-tk mice and varied in size, ranging from 4.8 to $14.8 \mathrm{~mm}$. In 12 week animals, a $2 \mathrm{~mm}$ region spanning the original fracture site was analyzed for all mice due to the WT mice having healed by this timepoint.

Finally, a rat monoclonal endomucin antibody (clone eBioV.7C7, 1:400 dilution; eBiocience, Santa Clara, CA, USA) was used to note the presence of vessels at the callus site. Briefly, all paraffin slides were deparaffinized in xylene and rehydrated in graded ethanols. Proteinase $\mathrm{K}$ was used for antigen retrieval followed by processing as described in the Vectastain Elite ABC HRP kit (PK-6104; Vector Laboratories, Burlingame, CA, USA). ImmPact DAB peroxidase (HRP) substrate (SK-4105; Vector Laboratories) was used for detection and all slides were imaged at 20x on a Nanozoomer slide scanner. Note that an isotype control antibody (Clone eBR2a, 1:400 dilution; eBioscience) was used as a negative control. These slides were analyzed qualitatively due to the complexity of the vessels appearance throughout the callus.

\section{Biomechanical Testing}

Bilateral femurs were dissected at 12 weeks post fracture and cleaned of all soft tissue ( $\mathrm{n}=6-9 / \mathrm{group})$. The ends of each femur were potted using polymethylmethacrylate (PMMA, Ortho-Jet, Land Dental) in 6mm diameter $x 12 \mathrm{~mm}$ length acrylic tubes. The bone was centered using a custom fixture, leaving approximately $4.2 \mathrm{~mm}$ of exposed bone (including the callus region) between potting tubes. All samples were wrapped in PBS soaked gauze to preserve hydration while the PMMA cured overnight. The following day, each sample was loaded into a custom-built torsion machine with a 25 in-oz load cell controlled with LabVIEW software (LabVIEW 2014, National Instrument, TX). The machine held one of the potted femur ends in a fixed position while rotating the other potted tube at $1 \mathrm{deg} / \mathrm{sec}$ until fracture. The maximum torque $(\mathrm{Nmm})$, rotation at maximum torque (degrees), and stiffness (Nmm/degree) were calculated from the resulting torque-rotation graphs (Matlab).

\section{$\underline{\text { Statistics }}$}

Prior to experiments, study sample sizes were calculated based on a power analysis with $\alpha=0.05$ and $\beta=0.20$ (https://www.stat.ubc.ca/ rollin/stats/ssize/n2.html). Estimates of sample variance and effect size were based on previous experimental data and biological importance. ${ }^{(23,29)}$ Target samples sizes for outcomes per experimental group were: MicroCT: $n=8$, Histology: $n=7$, Biomechanics: $n=10$. Actual sample sizes are noted above and in Results. A chi-square test was used to assess fracture union based on the Goldberg scale for each timepoint. An unpaired t-test was used to compare WT and Col1-tk microCT data taken at 3 weeks after fracture. TRAP histological quantification taken at 3 and 12 weeks post fracture was also analyzed using an unpaired t-test. Two-way ANOVA with Sidak's post hoc test to correct for multiple comparisons was used for in-vivo microCT (repeated factor: time; between factor: genotype). Ex-vivo microCT and torsion testing data were also analyzed using two-way ANOVA with Sidak's post hoc test (repeated factor: side [intact, fractured]; 
between factor: genotype). Significance was considered at $\mathrm{p}$ values $<0.05$. All data analysis was performed using Prism (Version 8; GraphPad Software, La Jolla, CA, USA).

\section{Results}

Bone Bridging and Callus Formation in Col1-tk Mice is Greatly Reduced at 3 Weeks.

To confirm targeting of tk+ cells with GCV, HSV-tk expression was evaluated in fracture callus at 2 weeks post fracture. WT mice given GCV displayed typical callus composition with both woven bone and cartilage, but no tk+ staining (Supplementary Figure 1A, $\left.\mathbf{A}^{\prime}\right)$. In Col1-tk mice dosed with vehicle $\left(\mathrm{H}_{2} \mathrm{O}\right)$, callus composition appeared normal and $\mathrm{tk}+$ expression was noted in cells within the woven bone and cartilage regions

(Supplementary Figure 1B, B'). However, in Col1-tk mice dosed with GCV, the fracture callus was reduced in size and lacked both woven bone and cartilage; some tk+ cells were present in the expanded periosteum (Supplementary Figure 1C, C').

Healing was evaluated by weekly radiographs which were blindly scored using a modified Goldberg score (Figure 2A). At 1 week after fracture, almost no bridging had occurred in either genotype. At 2 weeks, over $80 \%$ of the WT mice had at least one side bridged, compared to just over $50 \%$ of Col1-tk mice. After 3 weeks, there was some bridging in $100 \%$ of WT mice, and $83 \%$ had complete bridging; this was significantly different than Col1-tk mice, where there was some bridging in $77 \%$ of samples, but no samples were completely bridged, and $23 \%$ remained unbridged $\left(x^{2}, p<0.0001\right)$. Representative radiographic images demonstrate good and poor healing outcomes in WT and Col1-tk mice, respectively (Figure 2B). Additionally, 3D reconstructions of ex vivo microCT scans show a robust callus formed at the fracture site of WT femurs while the Col1-tk femurs showed greatly reduced callus formation (Figure 2B). Quantitative analysis of these scans (including callus and cortical bone) demonstrate an approximate 50\% reduction in BV and TV from WT to Col1-tk ( $p<$ 0.001; Figure 2C). Measures of density, i.e., vBMD and TMD, were greater in Col1-tk compared to WT femurs $(p<0.01)$, reflecting a larger relative contribution of the original (dense) cortical bone to the total bone within the ROI. In addition, the BV, TV, vBMD, and TMD values for Col1-tk calluses were closer to the average values for intact femurs (dashed line).

To further analyze healing, histological evaluation was completed using Picrosirius Red/Alcian Blue and EdU/DAPI staining (Figure 3). The WT femurs appeared fully (or nearly fully) bridged by a large woven bone callus, with only a small amount of cartilage (Figure 3A, $\mathbf{A}^{\prime}$ ). Bright EdU+ cells can be seen within representative fracture callus, indicating a localized increase in proliferation (Figure 3B, B'). In comparison, the Col1-tk femurs formed only a small callus, with less bone but more cartilage and fibrous tissues than WT (Figure 3C, C'). Col1-tk femurs had fewer EdU+ cells (Figure 3D, D'). A subset of fractured Col1-tk mice were given either EdU or both EdU/GCV for 1 week (Supplementary Figure 2). Col1-tk mice given only EdU displayed a typical fracture callus with EdU+ proliferative cells throughout (Supplementary Figure 2A, B). 
Similarly, while Col1-tk mice treated with both EdU and GCV displayed a smaller callus at the fracture site, there was still evidence of EdU+ cells (Supplementary Figure 2C, D).

TRAP and endomucin staining were performed to assess the presence of osteoclasts and vasculature, respectively (Figure 4). WT mice displayed an abundance of TRAP+ woven-bone lining osteoclasts along the callus surface (Figure 4A, A', A'). While the Col1-tk mice also had osteoclasts lining some woven bone (Figure 4B, B'), this was not seen consistently throughout the callus (Figure 4B'). $90 \%$ of the WT callus periphery was composed of bone, whereas the Col1-tk callus surface was only $19 \%$ bone, with the remaining $53 \%$ and $28 \%$ consisting of fibrous tissue and cartilage, respectively (Figure 4 C). Osteoclast length per callus length was significantly greater in WT compared to Col1-tk mice (22\% vs. $0.8 \%, p<0.001$; Figure 4D). Endomucin staining revealed a large amount of vasculature throughout the entire callus in the WT mice (Figure 4E, F). Comparatively, while the Col1-tk mice had some vasculature (Figure 4H), a majority of the fracture site displayed little to no endomucin staining (Figure 4G). 
A

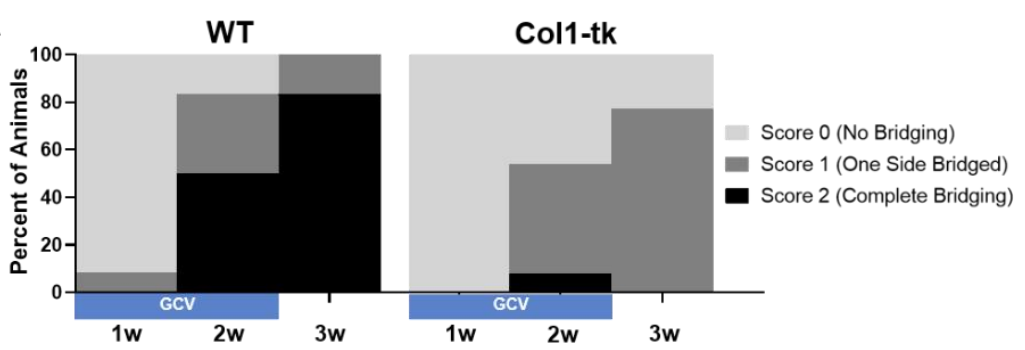

B

WT
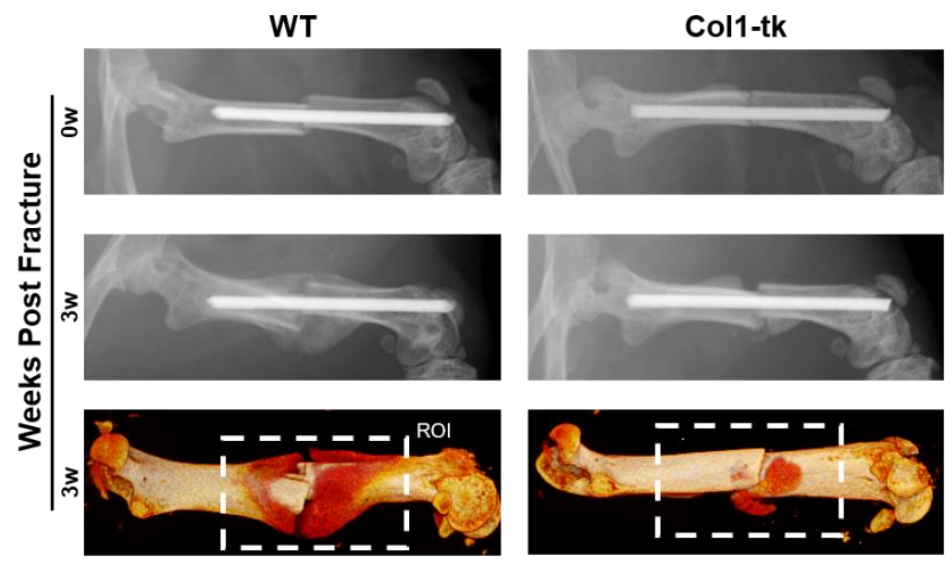

Low Density
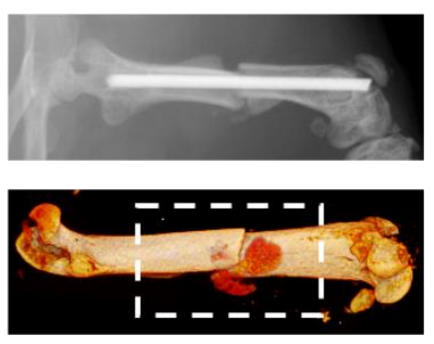

High Density

C
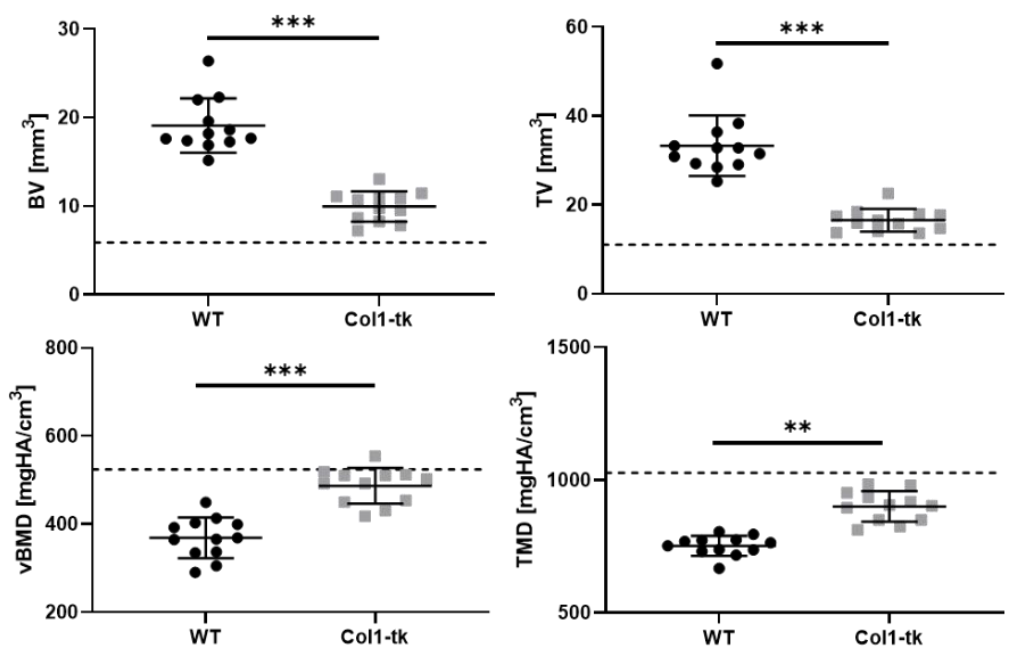

Figure 2. Following fracture, early healing was evaluated by weekly X-rays as well as ex vivo microCT. (A) Bridging evaluated by a modified Goldberg scale demonstrated the progression of callus bridging in WT mice as compared to reduced or absent bridging in Col1-tk mice. (B) This lack of bridging and reduced callus formation in Col1-tk mice can also be visualized in both radiographic images and microCT 3D reconstructions $(\mathrm{ROI}=6.3 \mathrm{~mm}$ region of interest for microCT analysis includes cortical bone and callus). (C) MicroCT quantification showed significantly less BV and TV in Col1-tk vs. WT mice, but significantly higher vBMD and TMD $\left({ }^{* *} p<0.01,{ }^{* * *} p<0.001\right)$. Average values of BV, TV, vBMD, and TMD for intact femurs are noted by a dashed line. 

available under aCC-BY-NC-ND 4.0 International license.
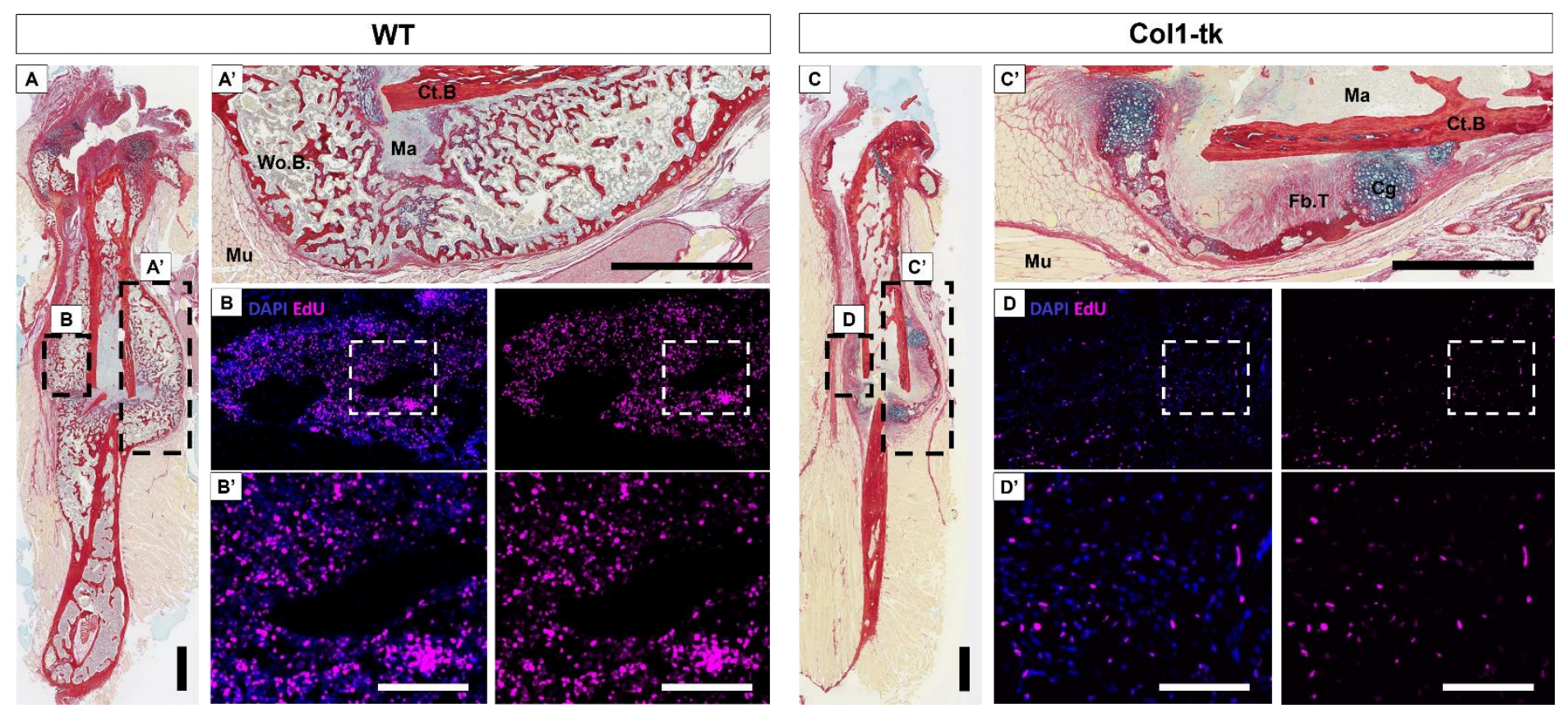

Figure 3. Healing at 3 weeks post fracture was qualitatively assessed using histological staining with either Picrosirius Red/Alcian Blue or EdU(pink)/DAPI(blue). (A, A') Sagittal sections from the fracture midpoint of WT mice had complete bridging with the callus almost entirely composed of woven bone (Wo.B; red stain). (B, B') There was abundant proliferation within the fracture callus as shown by the EdU stain in a representative cross-section. (C, C') The Col1-tk sections had a smaller callus composed of mostly cartilage (Cg; blue stain) and fibrous tissue (Fb.T), with little woven bone. (D, D') While proliferation is present at the callus site of Col1tk femurs, it is greatly reduced in both quantity and intensity as shown in a representative cross-section. Abbreviations: Cortical Bone = Ct.B; Cartilage = Cg; Fibrous Tissue = Fb.T.; Marrow = Ma; Muscle = Mu; Woven Bone $=$ Wo.B. Black and white scale bars denote $1 \mathrm{~mm}$ and $100 \mu \mathrm{m}$, respectively. 
bioRxiv preprint doi: https://doi.org/10.1101/2020.10.06.327288; this version posted November 27, 2020. The copyright holder for this preprint (which was not certified by peer review) is the author/funder, who has granted bioRxiv a license to display the preprint in perpetuity. It is made available under aCC-BY-NC-ND 4.0 International license.
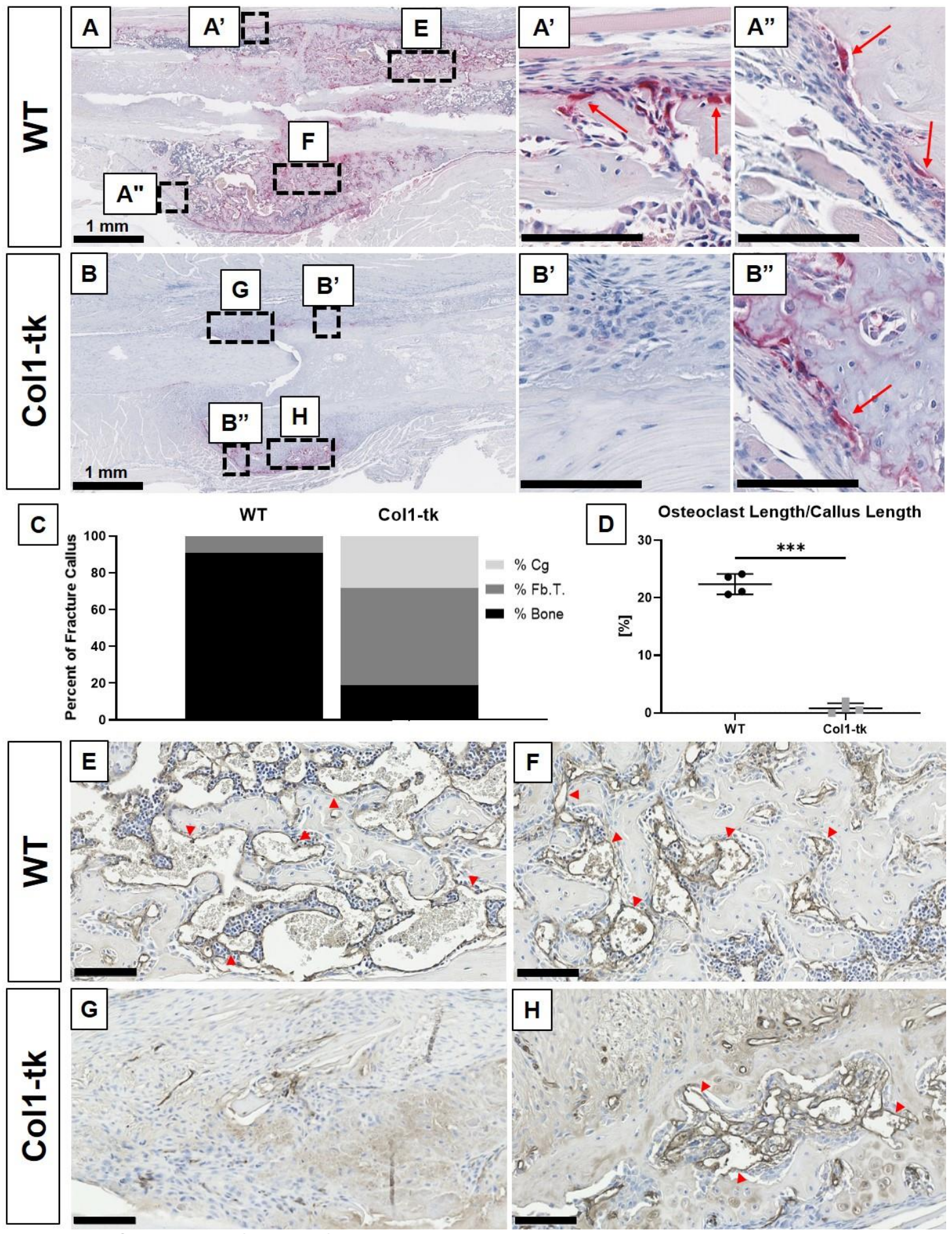

Figure 4. Osteoclast (TRAP+) activity and the presence of vessels was evaluated in WT and Col1-tk mice at 3 weeks post fracture. (A) WT mice displayed a large amount of (red) TRAP+ osteoclasts lining the woven bone along the callus surface, noted by red arrows ( $\left.A^{\prime}, A^{\prime \prime}\right)$. (B) The Col1-tk mice also had osteoclasts lining some woven bone, but this was greatly reduced (B', B"). (C) The callus surface of WT mice was primarily composed of bone and $(\mathrm{D})$ the ratio of the length of osteoclasts to woven bone was significantly higher as compared to Col1-tk mice $\left({ }^{* * *} p<0.001\right)$. The Col1-tk callus surface was largely composed of fibrous tissue (Fb.T) and cartilage $(\mathrm{Cg})$, in addition to bone. $(\mathrm{E}, \mathrm{F})$ Endomucin staining (brown) of the vessels was prevalent throughout the callus of WT mice, noted by red arrowheads. (G, H) Comparatively, the Col1-tk mice had some staining, but overall reduced vasculature. Black scale bars denote $100 \mu \mathrm{m}$ unless otherwise noted. 


\section{Radiographic Healing is Impaired in Col1-tk Mice 12 Weeks Post Fracture.}

To evaluate the effects of transient ablation of proliferating osteoblasts on long-term fracture healing, WT and Col1-tk mice were dosed with GCV for 2 or 4 weeks, the drug withdrawn, and the progression of healing followed until sacrifice at 12 weeks. WT mice, dosed for either 2 or 4 weeks, displayed a large callus formed around the fracture site at 2 weeks and this callus condensed over time (Figure 5). Based on blinded scoring, nearly all WT fractures had fully bridged after 4 weeks of healing. In comparison, while the Col1-tk mice also developed a callus, it was greatly reduced in size compared to WT mice and remained this way over 12 weeks. Any small mineralized callus present was visible by week 4 and remained consistent in size thereafter. For the Col1-tk mice dosed with GCV for 2 weeks (Figure 5A), between 5 and 12 weeks after fracture only 20 - 65\% of femurs appeared fully bridged. Similarly in the Col1-tk mice dosed with GCV for 4 weeks (Figure 5B), only 10 $-50 \%$ of femurs appeared fully bridged in the 5 to 12 weeks after fracture. The radiographic scores of WT and Col1-tk mice were significantly different from one another at all timepoints beginning at 2 weeks post fracture (2w GCV: $x^{2}, p<0.05$; and 4w GCV: $x^{2}, p<0.01$ ).
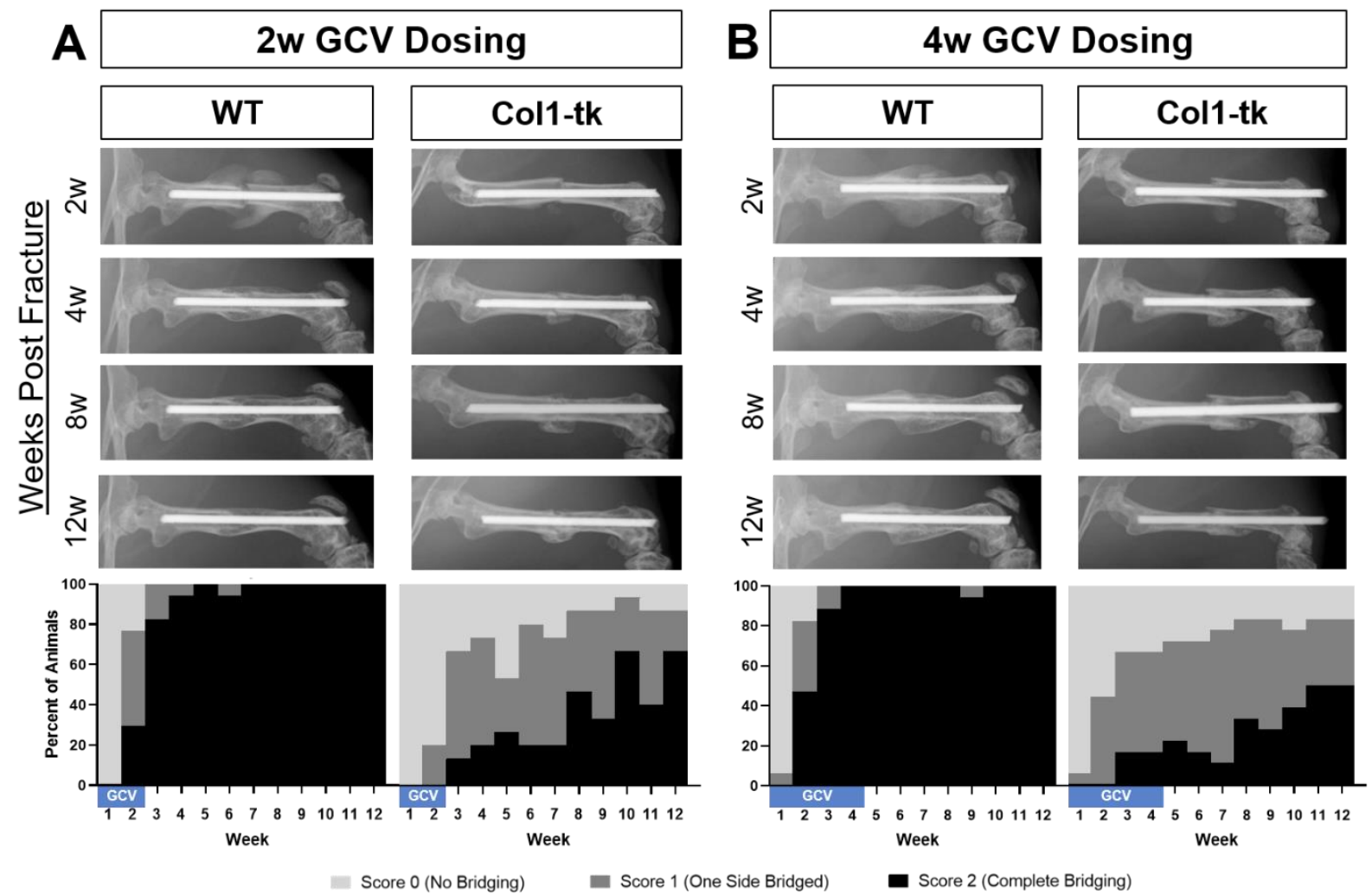

Figure 5. Radiographs were taken weekly following fracture until euthanasia at week 12. Representative $X$ rays are shown at 2, 4, 8, and 12 weeks for both WT and Col1-tk mice dosed with GCV for either (A) 2 or (B) 4 weeks immediately following fracture. Scoring was completed using a modified Goldberg scale. WT mice, regardless of dosing scheme, were fully bridged 4 weeks after fracture. By the end of the study only half of the Col1-tk fractures appeared completely bridged. Scoring of the radiographs demonstrated a significant difference between WT and Col1-tk mice with both $2 \mathrm{w}(x 2, p<0.05)$ and $4 \mathrm{w}$ dosing $(x 2, p<0.01)$. 
In Vivo MicroCT Shows Small Initial Callus Volume that Does Not Change over 12 Weeks in Col1-tk Mice.

To further track healing progression through 12 weeks, in vivo microCT scans were taken at 2 to 4 week intervals (Figure 6). Of the mice dosed with GCV for 2w, WT mice had a significantly larger callus volume and length at all timepoints compared to Col1-tk mice (Figure $6 A ; p<0.05$ ). In the $4 w$ GCV treated group, WT mice had a larger, longer callus compared to Col1-tk mice at 4 weeks post fracture (Figure 6B; $p<0.01$ ). Callus size in WT mice was greatest at 2 weeks and then reduced progressively with time, whereas the Col1-tk callus volume and length, for both dosing schemes, did not significantly change over time.

A
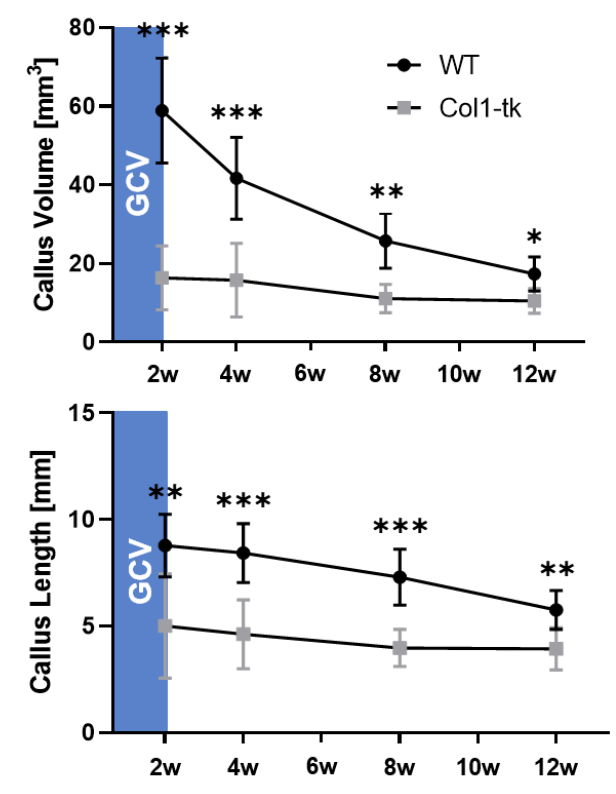
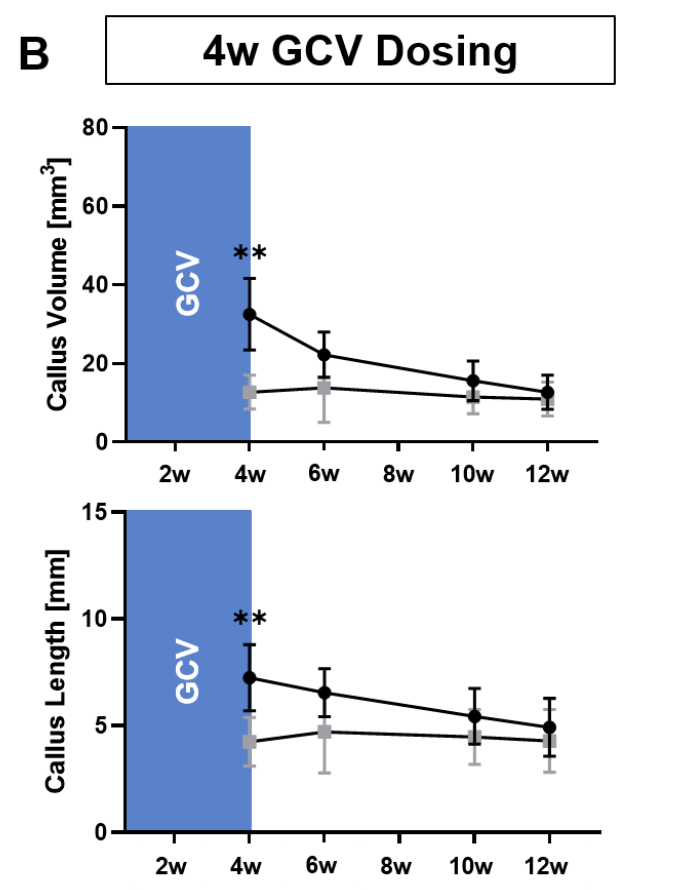

Figure 6. In vivo microCT was used to evaluate both callus volume $\left(\mathrm{mm}^{3}\right)$ and length $(\mathrm{mm})$ throughout the 12 weeks of fracture healing. (A) Following $2 w$ of GCV dosing, both WT callus volume and length were significantly larger than that of Col1-tk at 2, 4, 8, and 12 weeks. (B) 4w GCV dosing resulted in a significant difference between WT and Col1-tk callus volume and length at the 4 week timepoint. Notably, while WT calluses reduced volume and length over time, there was no significant change in Col1-tk callus size, for either dosing scheme, over time $\left({ }^{\star} p<0.05,{ }^{* *} p<0.01,{ }^{* * *} p<0.001\right)$.

\section{Ex Vivo MicroCT and Histology Show Lack of Bridging 12 Weeks Post Fracture in Col1-tk Mice.}

After 12 weeks of healing, animals were euthanized and both femurs dissected for microCT analysis (Figure 7). In WT mice, regardless of dosing scheme, the fracture site was completely bridged by a thin outer cortical shell at the margin of a consolidated callus, and a second inner cortex of similar outer diameter as the original cortex. There were no visible fracture surfaces. Calluses in the WT mice had similar BV as intact bones, but significantly greater TV (Figure 7A, 7B), indicating comparable bone mass distributed over a larger volume. Consequently, WT calluses had reduced VBMD and TMD compared to intact femur for both dosing schemes ( $p$ $<0.001$ ). By contrast, in Col1-tk mice much of the original cortical bone was still fragmented, with visible 
fracture surfaces and lack of bridging (Figure 7A, 7B). The callus region in Col1-tk mice had significantly greater BV and TV compared to the intact femur for both dosing schemes $(p<0.01)$, indicating greater bone mass distributed over a larger volume. Consequently, the fractured Col1-tk femurs had similar vBMD as intact bone.

Histological sections at the fracture site at 12 weeks were stained and imaged (Figure 8). All WT femurs had complete bridging with continuous cortical bone; there was no cartilage or fibrous tissue and the original fracture surfaces were not obvious. The thin outer and inner cortices seen on microCT were also evident as collagen-rich, aligned bone tissue. In contrast, the Col1-tk femurs all had clearly evident fracture surfaces, with regions that looked like original cortical bone. Col1-tk femurs had some calcified areas on the outside of the callus, and also had varying degrees of cartilage and fibrous tissue, demonstrating incomplete endochondral bone formation. When stained for TRAP+ osteoclasts, both the WT and Col1-tk callus periphery had some positive staining (Supplementary Figure 3A, A', A', B, B', B'). The periphery of the callus of both WT and Col1-tk mice was primarily composed of bone (100\% in WT and $73 \%$ in Col1-tk), but the Col1-tk fracture site also had fibrous tissue (Supplementary Figure 3C). Quantitative analysis of osteoclast length per callus length revealed fewer osteoclasts covering the WT callus than at 3 weeks (Figure 4), although still significantly more than Col1-tk ( $<$ 0.05; Supplementary Figure 3D). Endomucin staining revealed almost no vessels at the original site of fracture in WT mice (Supplementary Figure 3E, F) and minimal vasculature in Col1-tk mice (Supplementary Figure 3G, H). 
A
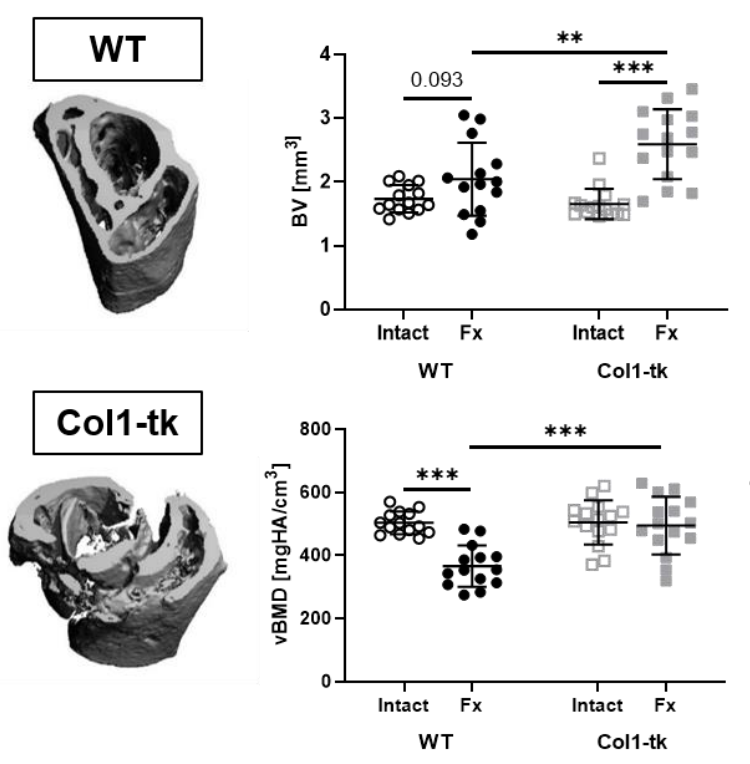

2w GCV Dosing
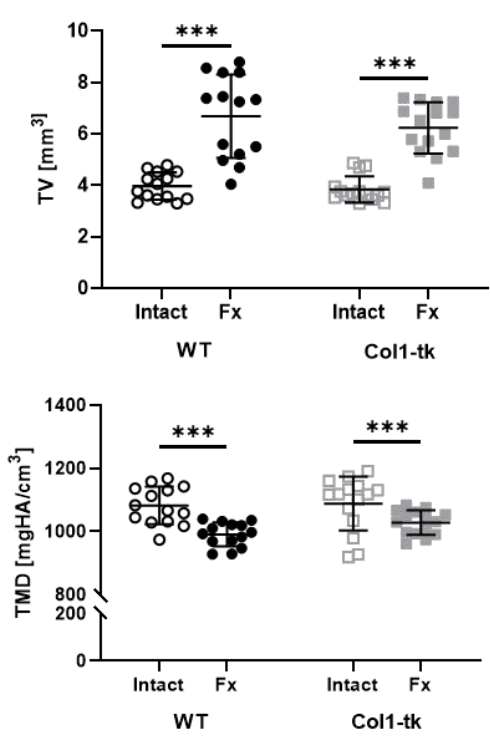

B
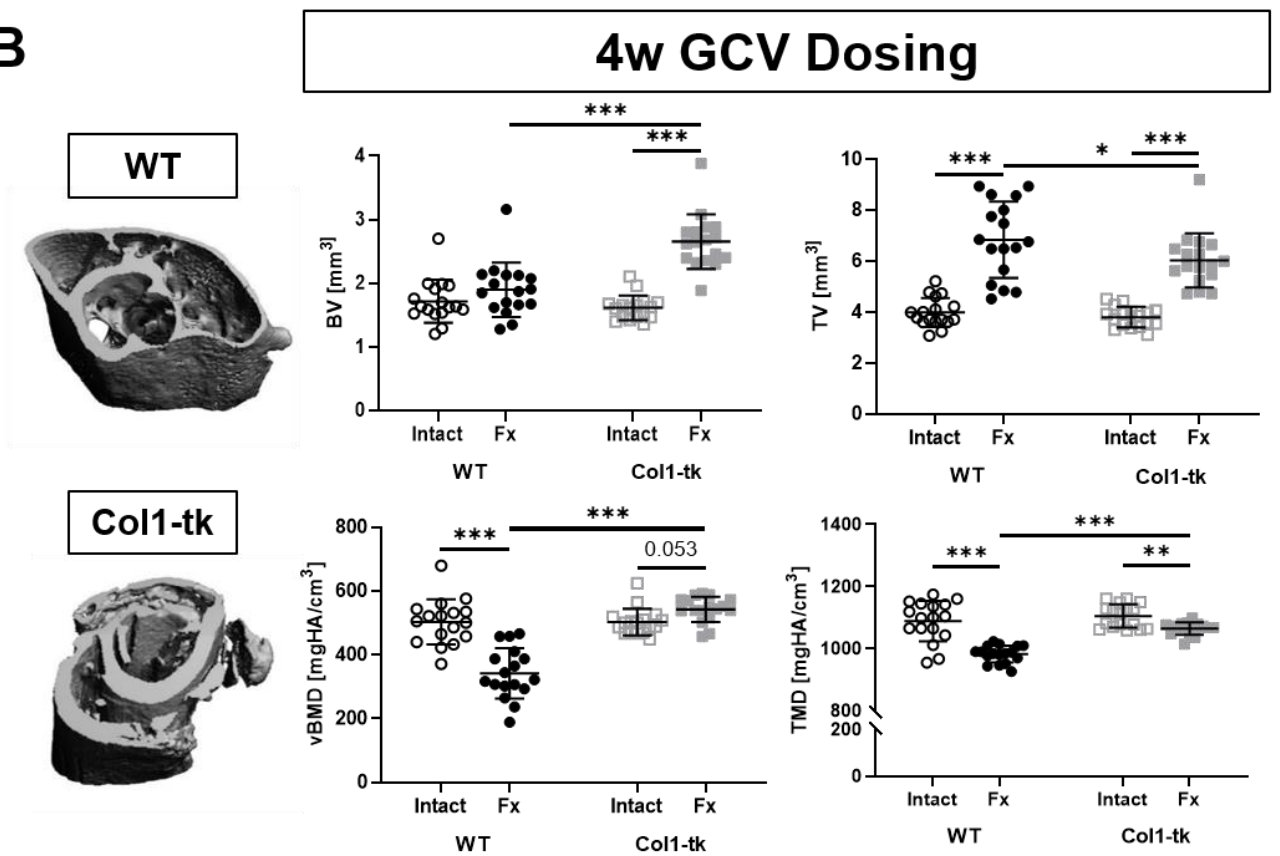

Figure 7. Ex-vivo microCT data for WT and Col1-tk intact and fractured (Fx) femurs for both (A) 2 and (B) 4w GCV dosing, analyzed at 12 weeks post fracture. Representative micro-CT 3D reconstructions displayed a thin, contiguous outer cortex integrated with an inner cortex in WT mice for both dosing schemes. In comparison, the Col1-tk reconstructions show evidence of the original cortical bone with poor consolidation and incomplete bridging at the callus site. (A) For $2 w$ GCV, WT mice had significantly different TV, vBMD, and TMD between intact and Fx femurs. Col1-tk had significantly different BV, TV, and TMD between intact and Fx femurs. (B) Similarly, 4w GCV also resulted in significantly different TV, vBMD, and TMD between the WT intact and Fx femurs. The Col1-tk mice also had significantly different BV, TV, and TMD between the intact and Fx femurs. Finally, the WT and Col1-tk Fx femurs had significantly different BV and vBMD for $2 w$ GCV dosing and BV, TV, vBMD, and TMD for 4w GCV dosing $\left({ }^{*} p<0.05,{ }^{* *} p<0.01,{ }^{* * *} p<0.001\right)$. 

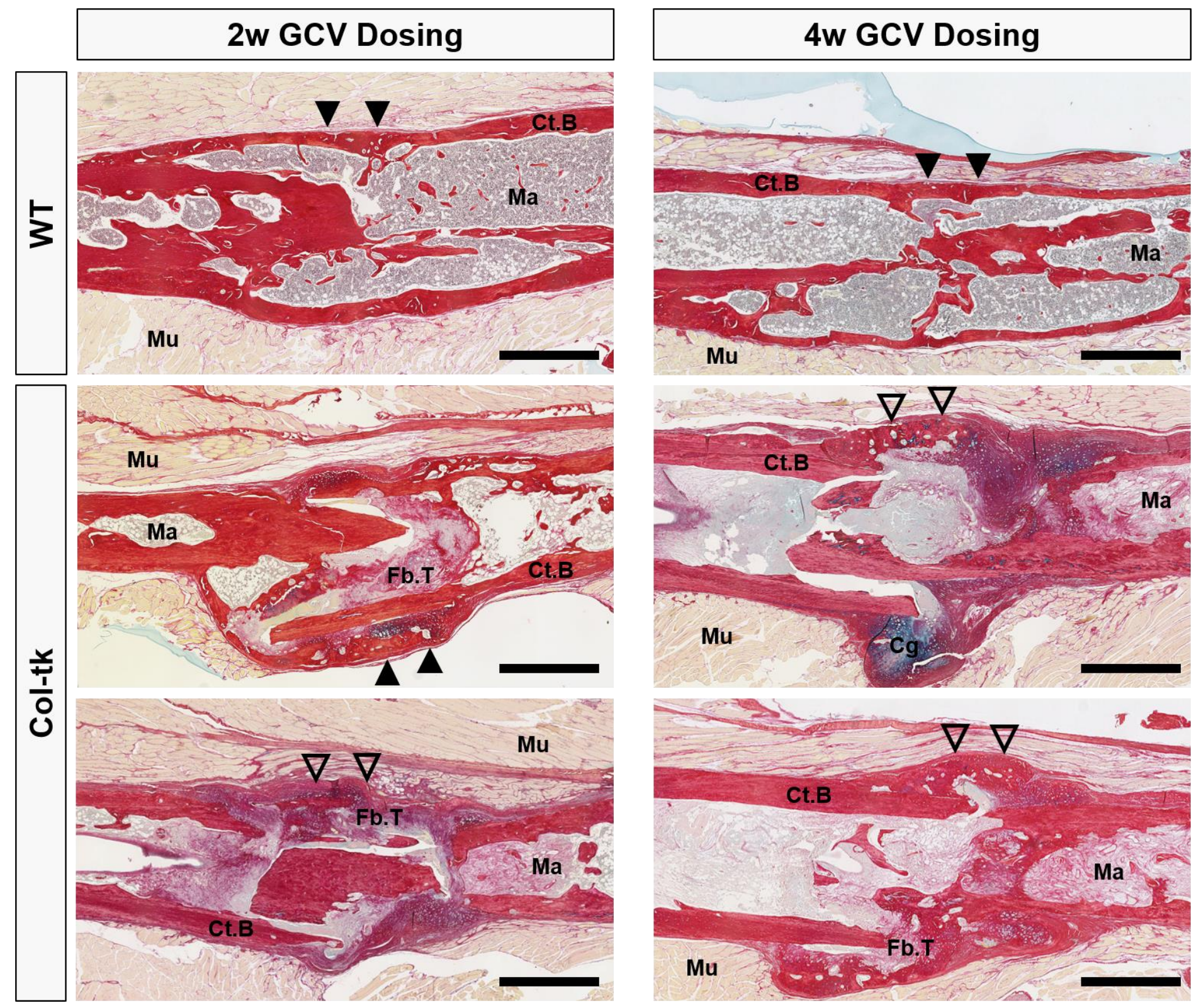

Figure 8. Representative Picrosirius Red/Alcian Blue staining of the WT and Col1-tk fracture site at 12 weeks post fracture. Regardless of GCV dosing timeline (2 or 4 week), WT mice had consistent, complete bridging by 12 weeks as shown by contiguous cortical bone (bright red staining; filled arrowheads), with little evidence of the original fracture site. The Col1-tk femur calluses had variable healing at 12 weeks (shown by two examples for each dosing group). The callus had some cortical bridging (filled arrowheads) in addition to pockets of woven bone at a still visible fracture site (open arrowheads). The Col1-tk fracture sites had some persistent cartilage and fibrous tissue. Abbreviations: Cortical Bone = Ct.B; Cartilage = Cg; Fibrous Tissue = Fb.T.; Marrow $=$ Ma; Muscle $=$ Mu. Black scale bars denote $1 \mathrm{~mm}$. 


\section{Col1-tk Mice Have Inferior Torsional Properties at 12 Weeks Post Fracture.}

To assess whether a functional union was achieved, torsional testing was completed on both intact and fractured ("healed") femurs from WT and Col1-tk mice (Figure 9). All intact femurs failed by spiral fracture within 10 degrees of rotation. In WT mice, the maximum torque and rotation at maximum torque of fractured femurs were not significantly different from intact femurs, indicating return to normal function. The only evidence of incomplete recovery in fracture femurs of WT mice was lower than normal stiffness in the $2 \mathrm{w}$ (but not 4w) GCV group. In stark contrast, the fractured femurs in Col1-tk mice had significantly reduced stiffness and increased rotation at maximum torque compared to intact femurs for both dosing groups, and decreased maximum torque in the $2 \mathrm{w} \mathrm{GCV}$ group (Figure 9A). Moreover, comparing fractured femurs between genotypes, Col1-tk femurs had significantly lower stiffness and greater rotation at maximum torque for both dosing timelines, indicating more compliant and less stable behavior, and maximum torque was significantly lower for the 4w GCV group (Figure 9B), indicating inferior strength. 

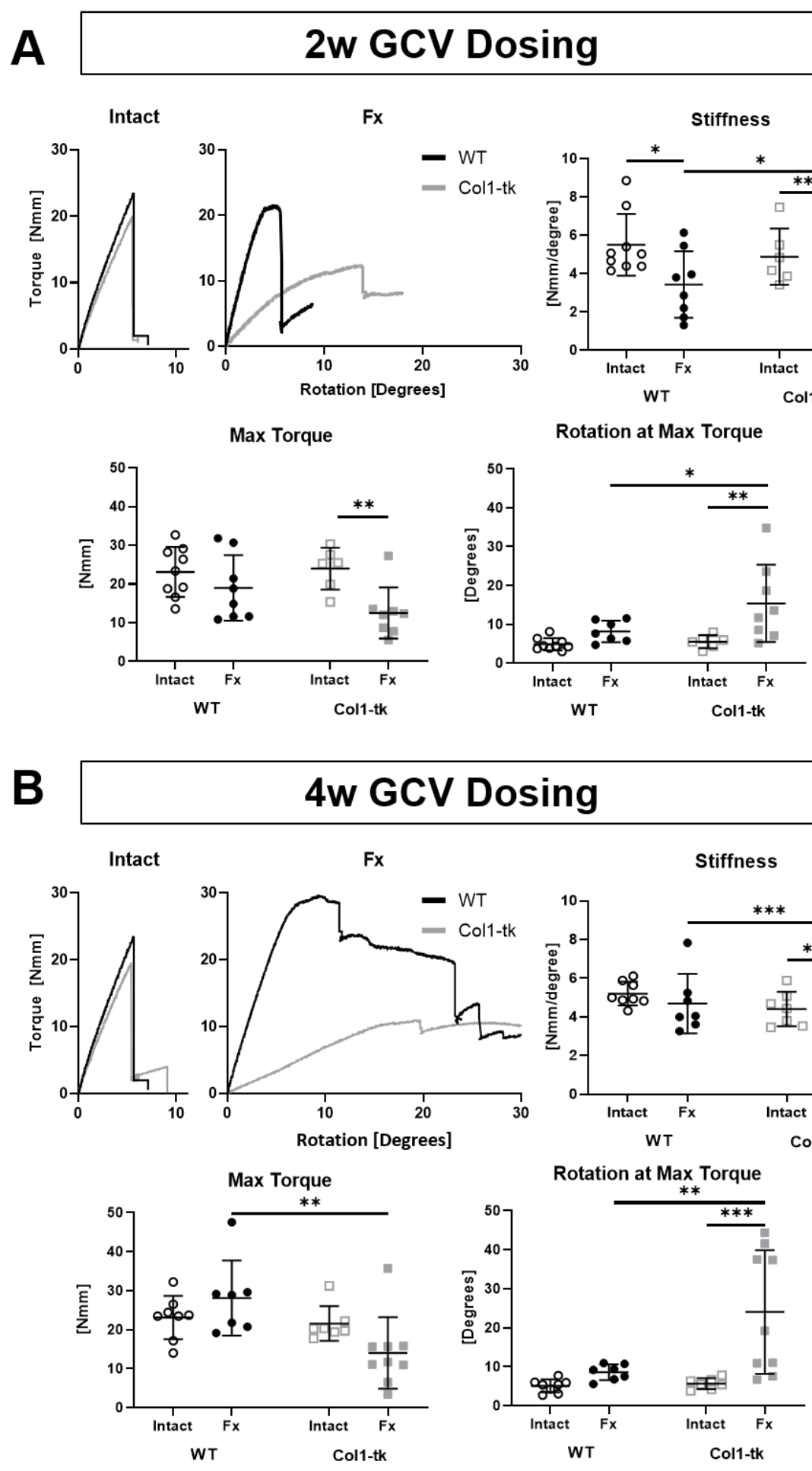

Figure 9. Biomechanical testing was completed to assess fracture stability and strength for (A) $2 \mathrm{w}$ and (B) $4 \mathrm{w}$ GCV dosed intact and fractures (Fx) femurs, analyzed at 12 weeks post fracture. Representative torquedisplacement curves are shown. Regardless of dosing scheme, intact femurs failed before reaching a rotation of 10 degrees. (A) In WT mice, 2w GCV intact and Fx femurs had significantly different stiffness. In Col1-tk, 2w GCV, stiffness, maximum torque, and rotation at maximum torque were all significantly different between intact and Fx femurs. (B) For the Col1-tk, 4w GCV, the stiffness and rotation at maximum torque were significantly different between intact and Fx femurs. Comparisons of Fx femurs between genotypes noted significant differences in stiffness and rotation at maximum torque for both GCV dosing timelines $\left({ }^{*} p<0.05,{ }^{* *} p<0.01\right.$, 


\section{Discussion}

We hypothesized that proliferation of periosteal osteoblast-lineage cells is required for fracture healing. Through a comprehensive assessment of healing in Col1-tk mice, we have provided evidence that ablation of proliferating osteoprogenitor cells during the initial weeks of fracture healing blunts callus formation, leading to impaired radiographic and biomechanical healing. This study therefore establishes the Col1-tk mouse as a new model of atrophic nonunion.

Periosteal cell proliferation is well documented during fracture healing ${ }^{(11,14,15,32)}$, and expansion of the mesenchymal progenitor cell population from the periosteum appears to account for the formation of cartilage and bone callus. ${ }^{(20,33)}$ However, a requirement for osteoprogenitor cell proliferation has not been directly tested. Previous studies have identified a peak in the proliferative response following fracture that extends from 2 to 14 days, suggesting a critical proliferative window for proper healing. ${ }^{(14-16)}$ But the molecular identity of the proliferating cell populations that contribute to the periosteal callus are not known. Recent work demonstrates that proliferation of 3.6Col1a1 expressing cells contributes to periosteal bone formation after non-injurious mechanical loading. ${ }^{(11,19,34)}$ Herein, using the Col1-tk mouse, we have shown that proliferation of $3.6 \mathrm{Col} 1 \mathrm{a} 1$ expressing cells is essential for fracture healing. By targeting the proliferation of these osteoblast lineage cells and ablating them through exposure to GCV, cell proliferation and fracture callus formation were markedly reduced at early timepoints. Upon withdrawal of the drug after 2 or 4 weeks, the Col1-tk mice were unable to heal 12 weeks post fracture, analogous to what is seen clinically in atrophic nonunion patients. Note that some proliferation was observed in Col1-tk mice, and there was a small mineralized callus evident radiographically and histologically. This may be explained by less than $100 \%$ efficiency of the tk-GCV strategy to ablate proliferating 3.6Col1a1 expressing cells, or may reflect contribution of a non-3.6Col1a1 osteoprogenitor cell population. It is also possible that the callus derives from endochondral ossification whereby post-mitotic chondrocytes transform directly to osteoblasts. ${ }^{(32)}$ Nevertheless, the striking reduction in callus formation, impaired callus mechanical strength, and overall inability to recover from the dosing-induced nonunion demonstrates the critical role of 3.6Col1a1 cell proliferation in fracture healing and further supports their essential function in bone formation. ${ }^{(18,19)}$

Despite recognition that cell proliferation is a hallmark of fracture healing, the critical window for its contribution to successful healing has not been identified. In rodents, proliferation peaks during the first 2 weeks after fracture, and complete bone bridging and recovery of mechanical properties takes approximately 4 weeks. ${ }^{(14-16,22)}$ We therefore selected 2 and 4 weeks for the durations of GCV dosing. We anticipated that blocking osteoblastic cell proliferation during the entire 4-week healing time course would lead to a permanent nonunion. In contrast, we were unsure whether withdrawal of GCV after 2 weeks might lead to a "rebound" of cell proliferation and eventual (delayed) union. Our results show that the two dosing schemes led to similar outcomes; both prevented healing over the 12 week study duration and led to nonunion. Thus, in mice, proliferation during the first 2 weeks of healing is essential to a full recovery, and a 2-week course of GCV in Col1-tk mice is sufficient to induce nonunion. This finding suggests two possibilities: the local signals that drive cell proliferation are transient, or the proliferative potential of osteoprogenitors is exhausted after 2 weeks of 


\section{GCV treatment.}

One implication of this study is that we have established conditions for an atrophic nonunion without additional local injury (beyond the initial fracture). Clinically, atrophic nonunions are characterized by sparse or absent radiographic callus with primarily fibrous tissue at the fracture site, although cartilage and bone can also be present. ${ }^{(4,10,35-37)}$ Available evidence also supports that atrophic callus tissue is not uniformly avascular. ${ }^{(10,36)}$ The radiographic and histological findings in Col1-tk mice have strong concordance with clinical observations, including minimal radiographic callus, heterogeneous callus tissue with majority fibrous tissue but also some cartilage and bone, and both avascular and vascularized regions. There are many described models of atrophic nonunion in large animals and rodents created by mechanical or thermal disruption of periosteum and bone at the fracture site. ${ }^{(6,8,25,38-46)}$ For example, Garcia et al. ${ }^{(25)}$ created approximately 2 mm segmental defects with periosteal stripping in mice femora, and observed atrophic nounion after 15 weeks. A recent study by Wang et al. ${ }^{(47)}$ demonstrated a nonsurgical atrophic nonunion model using radiation to induce periosteal damage. As fracture is a late side effect of radiation therapy, their model provides an appropriate model of the delayed healing response in that clinical setting. However, while these approaches result in atrophic nonunion, such invasive methods are not always representative of clinical nonunions where osseous regeneration has been arrested by a disturbance of metabolic pathways. ${ }^{(1,9,10)}$ Thus, a need has remained for the development of relevant, pre-clinical atrophic nonunion models to study underlying biological processes and to test therapeutic interventions. The Col1-tk mouse provides such a model, with a novel "failure of biology" that mimics many features of clinical atrophic nonunions.

There are several limitations to the successful use of the Col1-tk model, as well as suggestions for future studies. Due to the ability of the 2 week GCV dosing scheme to prevent recovery from the fracture and subsequent development of a nonunion, it is of interest to explore shorter windows of proliferative ablation. A shorter dosing scheme could be used to further examine the potential for rescue of callus formation. Additionally, the dosing start time could be delayed to evaluate the point at which fracture healing progression has gained enough momentum to not be affected by this proliferation ablation. This fracture model used an intramedullary pin for fracture stabilization. Other options include intramedullary locking nail or compression screw, external fixator, a pin-clip device, and locking plates. ${ }^{(48)}$ It is important to consider potential stress shielding with various models as it can cause asymmetric callus formation or even prevent a periosteal response. ${ }^{(49)}$ It would also be of interest to vary the fracture model by both type and location. While the femur is accepted as appropriate for studying fracture healing, other bones such as the tibia, ulna, rib, radius, and mandible could be useful alternatives. ${ }^{(48)}$ In addition, the full fracture model from this study heals by both intramembranous and endochondral healing. ${ }^{(27,28)}$ A stress fracture model could also be used to focus primarily on intramembranous ossification. ${ }^{(50,51)}$

In conclusion, we have identified a critical role for proliferation of the 3.6Col1a1 cell population in the first 2 weeks of fracture healing, and developed a novel murine model of atrophic nonunion. We utilized a Col1tk mouse model that, when dosed with GCV for 2 or 4 weeks, effectively blunted osteoblast proliferation, leading to impaired callus formation, and radiographic and biomechanical nonunion 12 weeks after fracture. The importance of our study is supported by the clinical prevalence of atrophic nonunion, and the expressed 
need for a relevant model to further study the biology of nonunion. This model can be used in future studies to test new intervention techniques to rescue atrophic nonunion.

\section{Disclosures:}

The authors would like to disclose that Dr. Matthew Silva is on the Board of Directors for the Orthopaedic Research Society. Dr. Anna Miller is on the Board of Directors for OTA and AAAM, the Editorial Board for JOT and JBJS, and a consultant for Smith \& Nephew. All other authors have no financial conflicts of interest with the submission of this manuscript.

\section{Acknowledgements:}

This work was supported by funding from NIAMS (R01 AR050211, P30 AR057235, R21 AR076636-01, T32 AR060719, and F32 AR076191-01). The authors would like to thank the Washington University in St. Louis Musculoskeletal Research Center (MRC) Cores and staff for assistance. Specifically, thanks to Yung Kim for all X-ray and microCT (Scanco) acquisition assistance. Also thanks to both Crystal Idleburg and Samantha Coleman for histological processing and sectioning of all specimens. Thanks also to Dennis Oakley of the Washington University in St. Louis Center for Cellular Imaging (WUCCI) Core and Heather Zannit for training and frozen section imaging assistance. Paraffin histological images were taken with the Nanozoomer at Alafi Neuroimaging Core (S10 RR027552). Finally, thanks to Nicole Migotsky for torsion testing and LabVIEW software instruction. 3.6Col1a1-tk mice were kindly provided by the labs of Drs. Robert Jilka and Charles O'Brien (University of Arkansas for Medical Sciences, Little Rock, AR, USA).

Authors' Roles: Study design: KRH, JAM, MJS. Study conduct: KRH, DAWS, SY, JAM, AH, DS. Data collection: KRH, DAWS, SY, JAM, EGB, DS. Data analysis: KRH, DAWS, SY, JAM, AH, EGB. Data interpretation: KRH, JAM, ANM, MJS. Drafting manuscript: KRH. Revising manuscript: KRH, JAM, MJS. Approving final version of manuscript: $\mathrm{KRH}$, DAWS, SY, JAM, AH, EGB, DS, ANM, MJS. KRH takes responsibility for integrity of data analysis.

\section{References:}

1. Choi P, Ogilvie C, Thompson Z, Miclau T, Helms JA. Cellular and molecular characterization of a murine non-union model. Journal of Orthopaedic Research. 2004;22(5):1100-7.

2. Nandra R, Grover L, Porter K. Fracture non-union epidemiology and treatment. Trauma. 2016;18(1):311.

3. Einhorn TA. Enhancement of fracture-healing. The Journal of bone and joint surgery American volume. Jun 1995;77(6):940-56. Epub 1995/06/01.

4. Cadet ER, Yin B, Schulz B, Ahmad CS, Rosenwasser MP. Proximal humerus and humeral shaft nonunions. The Journal of the American Academy of Orthopaedic Surgeons. Sep 2013;21(9):538-47. Epub 2013/09/03.

5. Mills LA, Simpson AH. The relative incidence of fracture non-union in the Scottish population (5.17 million): a 5-year epidemiological study. BMJ open. 2013;3(2). Epub 2013/02/12. 
bioRxiv preprint doi: https://doi.org/10.1101/2020.10.06.327288; this version posted November $27,2020$. The copyright holder for this preprint (which was not certified by peer review) is the author/funder, who has granted bioRxiv a license to display the preprint in perpetuity. It is made available under aCC-BY-NC-ND 4.0 International license.

6. Mills LA, Simpson AH. In vivo models of bone repair. J Bone Joint Surg Br. Jul 2012;94(7):865-74. Epub 2012/06/27.

7. $\quad$ Miclau T. Intl Society for Fracture Repair. New Orleans2018.

8. Boyan BD, Caplan AI, Heckman JD, Lennon DP, Ehler W, Schwartz Z. Osteochondral progenitor cells in acute and chronic canine nonunions. Journal of orthopaedic research : official publication of the Orthopaedic Research Society. Mar 1999;17(2):246-55. Epub 1999/04/30.

9. Gómez-Barrena E, Rosset P, Lozano D, Stanovici J, Ermthaller C, Gerbhard F. Bone fracture healing: cell therapy in delayed unions and nonunions. Bone. Jan 2015;70:93-101. Epub 2014/08/06.

10. Panteli M, Pountos I, Jones E, Giannoudis PV. Biological and molecular profile of fracture non-union tissue: current insights. J Cell Mol Med. Apr 2015;19(4):685-713. Epub 2015/03/03.

11. Zuscik MJ. Skeletal Healing. In: Rosen CJ, editor. Primer on the Metabolic Bone Diseases and Disorders of Mineral Metabolism2013.

12. Colnot C, Zhang X, Knothe Tate ML. Current insights on the regenerative potential of the periosteum: molecular, cellular, and endogenous engineering approaches. Journal of orthopaedic research : official publication of the Orthopaedic Research Society. Dec 2012;30(12):1869-78. Epub 2012/07/11.

13. Duchamp de Lageneste O, Julien A, Abou-Khalil R, Frangi G, Carvalho C, Cagnard N, et al. Periosteum contains skeletal stem cells with high bone regenerative potential controlled by Periostin. Nature communications. Feb 22 2018;9(1):773. Epub 2018/02/24.

14. Li G, White G, Connolly C, Marsh D. Cell proliferation and apoptosis during fracture healing. Journal of bone and mineral research : the official journal of the American Society for Bone and Mineral Research. May 2002;17(5):791-9. Epub 2002/05/15.

15. Iwaki A, Jingushi S, Oda Y, Izumi T, Shida JI, Tsuneyoshi M, et al. Localization and quantification of proliferating cells during rat fracture repair: detection of proliferating cell nuclear antigen by immunohistochemistry. Journal of bone and mineral research : the official journal of the American Society for Bone and Mineral Research. Jan 1997;12(1):96-102. Epub 1997/01/01.

16. Wildemann B, Schmidmaier G, Ordel S, Stange R, Haas NP, Raschke M. Cell proliferation and differentiation during fracture healing are influenced by locally applied IGF-I and TGF-beta1: comparison of two proliferation markers, PCNA and BrdU. Journal of biomedical materials research Part B, Applied biomaterials. Apr 15 2003;65(1):150-6. Epub 2003/03/13.

17. Serowoky MA, Arata CE, Crump JG, Mariani FV. Skeletal stem cells: insights into maintaining and regenerating the skeleton. Development (Cambridge, England). Mar 11 2020;147(5). Epub 2020/03/13.

18. Kalajzic I, Kalajzic Z, Kaliterna M, Gronowicz G, Clark SH, Lichtler AC, et al. Use of Type I Collagen Green Fluorescent Protein Transgenes to Identify Subpopulations of Cells at Different Stages of the Osteoblast Lineage. Journal of Bone and Mineral Research. 2002;17(1):15-25.

19. Zannit HM, Brodt MD, Silva MJ. Proliferating osteoblasts are necessary for maximal bone anabolic response to loading in mice. The FASEB Journal.n/a(n/a).

20. Colnot $\mathrm{C}$. Skeletal cell fate decisions within periosteum and bone marrow during bone regeneration. Journal of bone and mineral research : the official journal of the American Society for Bone and Mineral Research. Feb 2009;24(2):274-82. Epub 2008/10/14.

21. Jilka RL, O'Brien CA, Ali AA, Roberson PK, Weinstein RS, Manolagas SC. Intermittent PTH stimulates periosteal bone formation by actions on post-mitotic preosteoblasts. Bone. Feb 2009;44(2):275-86. Epub 2008/11/18.

22. Garcia P, Histing T, Holstein JH, Klein M, Laschke MW, Matthys R, et al. Rodent animal models of delayed bone healing and non-union formation: a comprehensive review. Eur Cell Mater. Jul 16 2013;26:1-12; discussion -4. Epub 2013/07/17.

23. Liu X, McKenzie JA, Maschhoff CW, Gardner MJ, Silva MJ. Exogenous hedgehog antagonist delays but does not prevent fracture healing in young mice. Bone. Oct 2017;103:241-51. Epub 2017/07/25.

24. Morshed S. Current Options for Determining Fracture Union. Adv Med. 2014;2014:708574-. Epub 2014/09/14.

25. Garcia P, Holstein JH, Maier S, Schaumloffel H, Al-Marrawi F, Hannig M, et al. Development of a reliable non-union model in mice. J Surg Res. Jun 1 2008;147(1):84-91. Epub 2007/12/07.

26. Gardner MJ, Putnam SM, Wong A, Streubel PN, Kotiya A, Silva MJ. Differential fracture healing resulting from fixation stiffness variability: a mouse model. J Orthop Sci. May 2011;16(3):298-303. Epub 2011/04/01.

27. Einhorn TA. The cell and molecular biology of fracture healing. Clin Orthop Relat Res. 1998;355. 
28. Bonnarens F, Einhorn TA. Production of a standard closed fracture in laboratory animal bone. Journal of orthopaedic research : official publication of the Orthopaedic Research Society. 1984;2(1):97-101. Epub 1984/01/01.

29. McKenzie JA, Maschhoff C, Liu X, Migotsky N, Silva MJ, Gardner MJ. Activation of hedgehog signaling by systemic agonist improves fracture healing in aged mice. Journal of Orthopaedic Research. 2019/01/01 2019;37(1):51-9.

30. Goldberg VM, Powell A, Shaffer JW, Zika J, Bos GD, Heiple KG. Bone grafting: role of histocompatibility in transplantation. Journal of orthopaedic research : official publication of the Orthopaedic Research Society. 1985;3(4):389-404. Epub 1985/01/01.

31. Bouxsein ML, Boyd SK, Christiansen BA, Guldberg RE, Jepsen KJ, Müller R. Guidelines for assessment of bone microstructure in rodents using micro-computed tomography. Journal of bone and mineral research : the official journal of the American Society for Bone and Mineral Research. Jul 2010;25(7):1468-86. Epub 2010/06/10.

32. Bahney CS, Zondervan RL, Allison P, Theologis A, Ashley JW, Ahn J, et al. Cellular biology of fracture healing. Journal of orthopaedic research : official publication of the Orthopaedic Research Society. Jan 2019;37(1):35-50. Epub 2018/10/30.

33. Zhang X, Xie C, Lin ASP, Ito H, Awad H, Lieberman JR, et al. Periosteal progenitor cell fate in segmental cortical bone graft transplantations: implications for functional tissue engineering. Journal of bone and mineral research : the official journal of the American Society for Bone and Mineral Research. 2005;20(12):2124-37. Epub 2005/08/08.

34. Shah K, Majeed Z, Jonason J, O'Keefe RJ. The role of muscle in bone repair: the cells, signals, and tissue responses to injury. Current osteoporosis reports. Jun 2013;11(2):130-5. Epub 2013/04/18.

35. Bajada S, Marshall MJ, Wright KT, Richardson JB, Johnson WE. Decreased osteogenesis, increased cell senescence and elevated Dickkopf-1 secretion in human fracture non union stromal cells. Bone. Oct 2009;45(4):726-35. Epub 2009/06/23.

36. Reed AA, Joyner CJ, Brownlow HC, Simpson AH. Human atrophic fracture non-unions are not avascular. J Orthop Res. May 2002;20(3):593-9. Epub 2002/06/01.

37. Guerkov HH, Lohmann CH, Liu Y, Dean DD, Simon BJ, Heckman JD, et al. Pulsed electromagnetic fields increase growth factor release by nonunion cells. Clin Orthop Relat Res. Mar 2001(384):265-79. Epub 2001/03/16.

38. Markel MD, Bogdanske JJ, Xiang Z, Klohnen A. Atrophic nonunion can be predicted with dual energy xray absorptiometry in a canine ostectomy model. J Orthop Res. Nov 1995;13(6):869-75. Epub 1995/11/01.

39. Oni OOA. A non-union model of the rabbit tibial diaphysis. Injury. 1995/11/01/ 1995;26(9):619-22.

40. Brownlow HC, Simpson AH. Metabolic activity of a new atrophic nonunion model in rabbits. Journal of orthopaedic research : official publication of the Orthopaedic Research Society. May 2000;18(3):43842. Epub 2000/08/11.

41. Park SH, Silva M, Bahk WJ, McKellop H, Lieberman JR. Effect of repeated irrigation and debridement on fracture healing in an animal model. Journal of orthopaedic research : official publication of the Orthopaedic Research Society. Nov 2002;20(6):1197-204. Epub 2002/12/11.

42. Kokubu T, Hak DJ, Hazelwood SJ, Reddi AH. Development of an atrophic nonunion model and comparison to a closed healing fracture in rat femur. Journal of orthopaedic research : official publication of the Orthopaedic Research Society. May 2003;21(3):503-10. Epub 2003/04/23.

43. Reed AA, Joyner CJ, Isefuku S, Brownlow HC, Simpson AH. Vascularity in a new model of atrophic nonunion. J Bone Joint Surg Br. May 2003;85(4):604-10. Epub 2003/06/10.

44. Kaspar K, Matziolis G, Strube P, Senturk U, Dormann S, Bail HJ, et al. A new animal model for bone atrophic nonunion: fixation by external fixator. Journal of orthopaedic research : official publication of the Orthopaedic Research Society. Dec 2008;26(12):1649-55. Epub 2008/06/13.

45. Tawonsawatruk T, Kelly M, Simpson H. Evaluation of native mesenchymal stem cells from bone marrow and local tissue in an atrophic nonunion model. Tissue Eng Part C Methods. Jun 2014;20(6):524-32. Epub 2013/10/24.

46. Roberto-Rodrigues M, Fernandes RM, Senos R, Scoralick AC, Bastos AL, Santos TM, et al. Novel rat model of nonunion fracture with vascular deficit. Injury. Apr 2015;46(4):649-54. Epub 2015/02/11.

47. Wang L, Tower RJ, Chandra A, Yao L, Tong W, Xiong Z, et al. Periosteal Mesenchymal Progenitor Dysfunction and Extraskeletally-Derived Fibrosis Contribute to Atrophic Fracture Nonunion. Journal of 
bioRxiv preprint doi: https://doi.org/10.1101/2020.10.06.327288; this version posted November 27,2020 . The copyright holder for this preprint

(which was not certified by peer review) is the author/funder, who has granted bioRxiv a license to display the preprint in perpetuity. It is made available under aCC-BY-NC-ND 4.0 International license.

bone and mineral research : the official journal of the American Society for Bone and Mineral Research. Mar 2019;34(3):520-32. Epub 2019/01/03.

48. Holstein JH, Garcia P, Histing T, Kristen A, Scheuer C, Menger MD, et al. Advances in the establishment of defined mouse models for the study of fracture healing and bone regeneration. Journal of orthopaedic trauma. May-Jun 2009;23(5 Suppl):S31-8. Epub 2009/04/29.

49. Kaur A, Mohan S, Rundle $\mathrm{CH}$. A segmental defect adaptation of the mouse closed femur fracture model for the analysis of severely impaired bone healing. Animal Models and Experimental Medicine.n/a(n/a).

50. Buettmann EG, Silva MJ. Development of an in vivo bone fatigue damage model using axial compression of the rabbit forelimb. Journal of biomechanics. Oct 3 2016;49(14):3564-9. Epub 2016/10/22.

51. Uthgenannt BA, Kramer MH, Hwu JA, Wopenka B, Silva MJ. Skeletal self-repair: stress fracture healing by rapid formation and densification of woven bone. Journal of bone and mineral research : the official journal of the American Society for Bone and Mineral Research. 2007/10// 2007;22(10):1548-56. 